JGG 2022:70:58-67

doi: 10.36150/2499-6564-N355
Cinical Geriatrics - Reviews

\section{Geriatric rehabilitation during COVID-19: a lesson learned}

\author{
Irma Ruslina Defi ${ }^{1}$, Ertania Nirmala ${ }^{1}$, Yustia Annisaa Thaharoh² \\ ${ }^{1}$ Physical Medicine and Rehabilitation Department, Faculty of Medicine, Dr. Hasan Sadikin Hospital/ \\ Padjadjaran University, Bandung, Indonesia; ${ }^{2}$ Faculty of Medicine, Jenderal Achmad Yani University, \\ Bandung, Indonesia
}

Severe acute respiratory syndrome coronavirus 2 (SARS-CoV-2) is a new strain of coronavirus that causes coronavirus disease 2019 (COVID-19) infection and is responsible for a deadly pandemic. The elderly population have a high risk to be infected by COVID-19 and tend to have worse outcomes compared to adult population. Elderly patients also have higher comorbidity than the whole population. Therefore, management of COVID-19 in the elderly needs special attention in terms of regarding drug doses, drug interactions, and side effects of the drugs given. Approach from Physical Medicine and Rehabilitation (PM\&R) in elderly population known as Geriatric Rehabilitation is required for COVID-19 because PM\&R will go through all phases of treatment during the acute, sub-acute, and long-term care phases. The targets are relieving symptoms, assisting in the mechanical ventilation weaning process, preventing decondition of the airway and other organ systems, and managing psychosocial aspects, especially in the vulnerable and high-risk elderly population. The geriatric rehabilitation approach to COVID-19 patients resulted in improved functional prognosis, optimized role of function, and improved Quality of Life.

Received: February 8, 2021

Accepted: September 6, 2021

\section{Correspondence}

Irma Ruslina Defi

Dr. Hasan Sadikin Hospital/Padjadjaran

University, Pasteur No. 38, Bandung, Jawa Barat, Indonesia. Tel: +62131690 8139

E-mail: irma.ruslina@unpad.ac.id

How to cite this article: Defi IR, Nirmala E, Thaharoh YA. Geriatric rehabilitation during COVID-19: a lesson learned. Journal of Gerontology and Geriatrics 2022;70:58-67. https://doi. org/10.36150/2499-6564-N355

(C) Copyright by Società Italiana

di Gerontologia e Geriatria (SIGG)

\section{(c) (1) $(9)$}

\section{OPEN ACCESS}

This is an open access article distributed in accordance with the CC-BY-NC-ND (Creative Commons Attribution-NonCommercial-NoDerivatives 4.0 International) license. The article can be used by giving appropriate credit and mentioning the license, but only for non-commercial purposes and only in the original version. For further information: https://creativecommons.org/licenses/by-nc-nd/4.0/deed.en
Key word: COVID-19, functional prognosis, geriatric rehabilitation, physical medicine and rehabilitation

\section{INTRODUCTION}

Severe acute respiratory syndrome coronavirus 2 (SARS-CoV-2) is a new strain of coronavirus that causes coronavirus disease 2019 (COVID-19) infection and causes the deadly pandemic. The World Health Organization (WHO) declared SARS-CoV-2 as an outbreak on March 2020 and reported that more than 30 million cases confirmed SARS-CoV-2 from 214 countries with death tolls reaching more than a million cases. Case Fatality Rate (CFR) globally is $3 \%$ and is increasing ${ }^{1,2}$. A study indicated this virus causes the worst impact with a higher fatality rate in the elderly and people with comorbidities like hypertension, cardiovascular disease, diabetes mellitus, chronic obstructive pulmonary disease (COPD), and chronic kidney disease (CKD) ${ }^{1,3-5}$.

A study by Guan et al. reported patients above 65 years old accounts for $15.1 \%$ of COVID-19 disease in China and Wu and McGoogan found patients more than 80 years old accounts for $3 \%$ of patients with COVID-19. are more vulnerable to infection and death, with $62 \%$ of deaths occurring Meanwhile, Yang and Yu's study in Wuhan, China, found that the elderly 
in patients over 60 years old, $81 \%$ of patients suffering from Acute Respiratory Disease Syndrome (ARDS), and 94\% requiring mechanical ventilation. A study in America showed $80 \%$ of death in patients with COVID-19 occurred in patients above 65 years old. It indicated that elderly people have a high risk of being infected by COVID-19 and have worse consequences than the general population ${ }^{1,6-8}$.

Along with the spread of the COVID-19 virus outbreak, the number of elderly patients with COVID-19 were increasing globally and these cases often resulted in life-threatening conditions, which burdened the public and world health care systems ${ }^{6}$. Therefore, COVID-19 control and Guidelines are needed in every country to decrease the spreading of this outbreak, reduce morbidity and mortality, increase safety and health community life, and maintain social stability ${ }^{1,3,6}$.

In the initial phase of the outbreak, acute sectors of the health system were the most affected, especially emergency service, Intensive Care Unit (ICU), laboratory, and imaging service. As time goes by, almost every sector of health care became involved, including acute postcare and rehabilitation ${ }^{9}$. Appropriate Physical Medicine and Rehabilitation (PM\&R) interventions to COVID-19 patients showed improved functional prognosis, optimized functional maintenance, and increased Quality of Life (QoL). However, there is a limitation of literature and research that investigate the approach of geriatric rehabilitation intervention for elderly with COVID-19.

Approach from PM\&R gives an important role in all phases of the treatment: in intensive care, critical care, and medical ward; in sub-acute phase; and long-term phase when the patients are discharged. The PM\&R management in the elderly is known as Geriatric Rehabilitation, which considers the needs of each individual based on the severity of their clinical conditions, malfunctioning, and the role of patients when returning and interacting with the community ${ }^{1,10-14}$.

This literature review will discuss the role of geriatric rehabilitation for the elderly with COVID-19. This study is expected to provide knowledge and hopefully later become guidelines for planning the geriatric rehabilitation management of elderly patients with COVID-19. In addition, it will also help to optimize the elderly's role of function, participation, and increase QoL.

\section{METHOD}

The selection of literature or data relevant to the topic was conducted through specific keywords using the computer-aided search engine. The literature or data consist of eBooks or journal articles that are not limited to any country or area in the world. The year of publication of the literature or data should not exceed ten years prior. Additional information sources needed to clarify the main literature or data are obtained from the reference section of the articles. The inclusion criteria for literature or data used was based on the content which explains geriatric rehabilitation for COVID-19, the impact of having a COVID-19 infection, and the main principles in the geriatric rehabilitation processes.

\section{COVID-19 INFECTION}

Since it was declared as a global pandemic in March 2020, confirmed COVID-19 cases reached more than eight million globally. Numerous studies have been conducted to investigate the clinical characteristic of COVID-19, including one study conducted at 522 hospitals in Wuhan, China. The characteristic of COVID-19 existing in this China study shows that the mean age of COVID-19 patients is 47 years, with more than $50 \%$ were male. The Centres for Disease Control and Prevention (CDC) reported that individuals over 65 years of age make up $17 \%$ of the total populations in the United States. However, they accounted for $31 \%$ of COVID-19 infections, $45 \%$ of hospitalizations, $53 \%$ of intensive care, and $80 \%$ of death caused by this disease. This suggests that older people are more likely to contract COVID-19 and have worse symptoms than the general population ${ }^{1,16,17}$.

Most of the symptoms present at admission are fever (43\%), cough (67\%), and in some patients, diarrhoea or other gastrointestinal complaints (3\%). The average incubations period is 2-7 days, with $5 \%$ of patients admitted to the ICU, $2.3 \%$ on ventilators, and $1.4 \%$ mortality ${ }^{3}$. Chest $X$-rays showed bilateral infiltrates, and chest CT-scans showed ground-glass opacity. Haematological examinations in most patients indicated lymphopenia. Other studies showed risk factors of ARDS and death that included being elderly and having comorbidities ${ }^{17-19}$.

\section{CLINICAL CHARACTERISTICS OF COVID-19 IN ELDERLY}

Niu et al. studied the clinical characteristics of elderly COVID-19 patient and reported the most common symptoms are fever (78.3\%) and coughing (56.7\%). Generally, older patients who are infected initially have fever, fatigue, dry cough, and gradually develop dyspnoea. In some patients, the symptoms progress to ARDS, septic shock, and even death 3,4,6,8,17.

In the Niu et al. study, forty percent of elderly patients had fever with temperature between $37.3-38.0^{\circ} \mathrm{C}$, $38.3 \%$ of patients had fever higher than $38^{\circ} \mathrm{C}$, only 
two patients had fever more than $39^{\circ} \mathrm{C}$, and $21.7 \%$ of patients had no fever ${ }^{6}$. This might be due to the decreased thermoregulation resulting from the ageing process. Complaints of low-grade fever and no fever, especially in older patients causes difficulty identifying and diagnosing COVID-19 in clinical practice ${ }^{3,6,8}$.

Liu et al. observed that there are more male elderly COVID-19 patients compared to female ${ }^{8}$. COVID-19 is thought to be more likely to infect adult males with chronic comorbidities due to their weaker immune function ${ }^{20}$. Meanwhile, Wang et al. reported that coagulation disorders, myocardial damage, and bacterial infection are more common in the elderly, leading to higher risk of death ${ }^{3}$. In addition, complications are common in the elderly when patients have bacterial infection, ARDS, Acute Coronary Syndrome (ACS), and liver enzyme abnormalities. Wang also reported that the elderly have higher rate of comorbidities than all population. These comorbidities include hypertension, diabetes, cardiovascular disease, COPD, CKD, and cerebrovascular disease ${ }^{3,5,20}$.

Supporting examinations for elderly patients with COVID-1 showed that:

1 elderly patients had significantly higher rate of elevated white blood cell counts and neutrophils compared to young and middle-aged patients ${ }^{3,8}$. This indicated that elderly patients infected by COVID-19 are more likely to have bacterial infections ${ }^{8}$;

2 elderly patients had significantly higher lymphocyte reduction than that of young and middle-aged patients $3,8,17$. The number of CD4+ and CD8+ lymphocytes was significantly lower in the elderly, indicating cellular immunity suppression. This is thought to be due to changes in the lung anatomy and muscle atrophy, which causes changes in the physiological function of the respiratory system, decreased respiratory clearance, decreased pulmonary reserve, and decreased defence function ${ }^{8}$. In addition, it has been reported that lymphocytes can be damaged by coronavirus due to damage to cytoplasmic components or apoptosis ${ }^{3}$;

3 elderly patients had significantly higher levels of CReactive Protein (CRP) compared to the young and middle-aged groups ${ }^{8,17}$;

4 increased urea and serum creatinine indicated worsening kidney function ${ }^{3}$;

5 lung imaging of elderly patients showed significantly higher incidence of multilobe ground-glass opacity than in young and middle-aged patients 8,17 . Lung scan is an examination method that can quickly confirm the diagnosis and monitor changes in a patient's condition. This examination is also used to assess disease severity and help predict the development of a more severe disease ${ }^{8}$.

\section{GERIATRIC REHABILITATION POINT OF VIEW}

The geriatric population are very vulnerable to COVID-19, so it is crucial to take precautions to prevent this population from contracting the disease. The prevention can be physical and social distancing, wearing masks and other prevention methods. In this implementation, it is also necessary to pay attention to the well-being and mental health of elderly patients. Management COVID-19 on the elderly patients differs from adults in the general population. Caution is needed because of the side effect of inpatient isolation, the drugs given to the patients, as well as drug interaction ${ }^{15}$. New evidence is emerging on the importance of lean body mass during periods of illness and recovery. Loss of mass, quality and function of skeletal muscle is a sign of sarcopenia, and it is a risk factor for increasing frailty, and predicting mobility and disability. This condition also often leads to loss of independence and reduced QoL 21-27.

On the other hand, elderly patient with obesity can trigger an inflammatory response and accelerate the onset of cytokine storm syndrome, which appears to play a role in increasing the risk of acute respiratory distress syndrome and non-respiratory complications. Chronic inflammation, which is associated with obesity, can contribute to the activation of the inflammatory cascade that leads to acute kidney failure and shock in COVID-19 patients ${ }^{28}$.

During bed rest in the hospital, physical inactivity can have a negative synergistic effect on muscle protein synthesis, favouring the subsequent onset of sarcopenia. The definition that is most cited is the one proposed by the European Working Group on Sarcopenia in Older People (EWGSOP) which stated that sarcopenia is a syndrome characterized by progressive and generalized loss of skeletal muscle mass and strength with a risk of adverse outcomes such as physical disability, poor quality of life, loss of skeletal muscle mass and strength that occurs with advancing age ${ }^{27}$. This disorder increases healthcare burden, limits independent life, decreases QoL, and exacerbates disability and death rates. Sarcopenia is related to multiple factors, especially chronic inflammation, hormonal changes, decrease in activity and malnutrition; and as such, can also occur even in a younger age ${ }^{29-31}$. Routine screening for sarcopenia should start as early as possible for elderly patients with COVID-19, focusing not only focus on COVID-19 infection itself, but on its impact to the musculoskletal system as well. Early detection and treatment of sarcopenia in elderly patients with COVID-19 may reduce morbidity and mortality during the current COVID-19 crisis $^{32}$.

The preservation of muscle mass and muscle function is increasingly recognized as a crucial factor for 
promoting healthy ageing and better outcomes in different healthcare settings. Physical activity are effective for preventing and mitigating sarcopenia, supporting recovery, and delay the development of disability. Longterm moderate-intensity physical activity can prevent mobility disability in elderly patients ${ }^{33}$. Physical activities can improve functional independence and reduce mortality, after controlling for potential confounders such as smoking, obesity, family history of cardiovascular disease, hypertension, cancer and diabetes ${ }^{34-36}$. Walking as soon as possible is the primary mode of physical activity for preventing major disability in mobility ${ }^{33}$.

\section{CHALLENGES AND OPPORTUNITIES FOR GERIATRIC REHABILITATION}

COVID-19 outbreak causes fear and suffering for the elderly around the world. The pandemic era is marked with uncertainties, although certain challenges and opportunities are expected to arise due to this pandemic. Through identifying challenges and opportunities, one can minimize the negative impact from the spread of COVID-19 and optimize the positive changes that may occur by increasing awareness, optimizing programs, and advocating for policies, especially in vulnerable elderly communities ${ }^{37-38}$.

The challenges of the COVID-19 pandemic in relation to the risk and specific impacts for the elderly can be broadly grouped into three categories.

\section{LIFE AND DEATH}

All age groups are at risk of contracting COVID-19, but the elderly are at a higher risk of death and experience more severe symptoms after infection ${ }^{1,38}$. About 66\% of people 70 years of age and over have at least one underlying condition, leading to an increased risk for severe symptoms COVID-19. In addition, the elderly may face age discrimination in medical care, triage, and life-saving therapy decisions. Globally, as many as half of the elderly in developing countries do not have access to essential health services. The pandemic has also decreased the priority for critical health services for non-COVID-19 diseases, increasing the risk in elderly lives ${ }^{38}$.

\section{VULNERABILITY AND NEGLECT}

Nursing homes and care institutions' vulnerability to the spread of COVID-19 has been reported to have claimed a tremendous toll due to neglect of health protocols and poor handling. In addition, the elderly who are quarantined or isolated from a family member or caregiver is also vulnerable to face a higher risk of violence, harassment, and neglect ${ }^{37,38}$.

\section{MentaL, SOCIAL AND ECONOMIC WELL-BEING}

This virus threatens the life and safety of the elderly and threatens their social network, access to health services, job, and their retirement. Elderly who usually receive home service is at risk of being affected by physical distancing and social distancing, especially on their mental health due to the prolonged isolation periods, exacerbated by the limited ability to access digital technology. Furthermore, the impact on income and unemployment is tremendous considering that the proportion of the elderly in the workforce has increased by nearly $10 \%$ globally over the last three decades. There are significant gaps in developing countries where less than $20 \%$ of retirement age population receive pension benefits, which means more than $80 \%$ of the elderly are not getting pension benefits. Social insurance can play a role in ensuring the welfare of the elderly, but this is a quite vast scope. This should be a special consideration for the government and society 37,38 .

Although the COVID-19 pandemic crisis presents many challenges, there are still opportunities to improve the QoL for the elderly population. These opportunities include improving connectivity with family, improving the relationship between generations, and reducing isolation through technology, improving self-care and management, and raising awareness through technology, laws and other policies. Professionals including Physiatrist (PM\&R specialist) who are concerned with the geriatrics can take advantage of these opportunities, and use them as references for developing programs 1,37,38.

\section{Improve connectivity}

a. Improve the elderly population's ability in working with technology and improve their skills in using online media;

b. Improve connectivity between families, generations and social communities, by increasing interaction, communication, and participation in family and community activities;

c. Strengthen social solidarity to face socio-economic issues ${ }^{37,38}$.

\section{Improve QoL}

a. Deal with social isolation, loneliness, and boredom with positive activities and programs, and actively participate in learning new things;

b. Seize more self-care and time management opportunities by changing the way the elderly think and act about their own physical and mental health, i.e. paying more attention to schedule (sleep, diet, exercise, social connections) and self-care skills in daily activities;

c. Increase awareness about the importance of planning and decision-making related to the end-of-life care and other legal documents; 
d. Use of proper monitoring for support and health care services for the elderly, and provide easy access to fulfil the rights of the elderly ${ }^{37,38}$.

\section{Expanding the professional workforce with specialization in geriatrics}

a. There are opportunities to solve complex geriatric problems by working with the elderly and advocating for public health policies, but not many professionals are involved ${ }^{37}$.

\section{THE ROLE OF GERIATRIC REHABILITATION IN THE MANAGEMENT OF ELDERLY PATIENTS WITH COVID-19}

The Chinese Centre for Disease Control published cohort data on adult COVID-19 patients requiring hospitalization, $61 \%$ of whom needed the ICU, with an average length of stay of 3 weeks ${ }^{12}$. It is predicted that the proportion of patients with a disability related to COVID-19 will grow rapidly. Rapid response from PM\&R specialists is essential to reduce disability, aid recovery, and optimize function, especially in acute care situations 9,12,13,23.

Elderly patients without or with minimal symptoms generally will recover entirely without long-term sequelae. However, elderly patients with COVID-19 will experience mild to severe symptoms which affects several body systems. Severe cases of COVID-19 are associated with the consequences of using ventilators, immobilization, physical decondition, muscle weakness, impaired cognition, delirium, swallowing and communication disorders, psychiatric disorders, psychosocial support, and prolonged bed rest 12-14,39.

The overall role of geriatric rehabilitation in the COVID-19 pandemic is to overcome and anticipate the impact of COVID-19 on the body system in acute, sub-acute, and long-term care phases, in order to maintain and optimize elderly patients' function and improve their QoL. The need for the geriatric rehabilitation approach is greater in elderly patients with co-morbidities and deteriorating health conditions associated with ageing. Goals should focus on the successful geriatric rehabilitation program of COVID-19 patients including returning to daily activities and community as well as to protect the health of rehabilitation team members ${ }^{11,40}$.

The geriatric rehabilitation needs for elderly with COVID-19 are divided according to their treatment phase, which includes acute, sub-acute, and long-term care. Medical rehabilitation professionals should be ready in the ICU, hospital wards, outpatient facilities, and in the community ${ }^{9,12,13,15}$.
Geriatric Rehabilitation programs in the COVID-19 pandemic should be centred on the needs and goals of the patient, and may include exercises, education, and advice on self-management strategies (including those for cognition, swallowing, and activities of daily living); respiratory techniques (such as breathing exercises and techniques); provision of assistive products; caregiver support and education; peer-to-peer groups; stress management; and home modification ${ }^{15}$.

Complications from COVID-19 in elderly can be reduced by:

1 providing interdisciplinary rehabilitation that starts early and continues during the acute phase of hospitalization;

2 providing patient/family education for self-care after leaving inpatient rehabilitation in the acute or subacute phase;

3 continuing rehabilitation care in an outpatient setting and at home through therapy either in person or via telehealth (telemedicine) ${ }^{39}$.

More attention is needed towards the mental wellbeing of the elderly because they are a high-risk population ${ }^{37,41}$. Based on a report in China, $37.1 \%$ of the elderly experience depression and anxiety due to the pandemic ${ }^{42}$. Meanwhile, in Greece, the prevalence of elderly with moderate-severe depression was $81.6 \%$, moderate-severe anxiety was $84.5 \%$, and sleep disorders $37.9 \%{ }^{43}$. This can increase the mortality in the elderly ${ }^{44}$. The guidelines were prepared through expert opinions in the field of rehabilitation globally and are based on a review of relevant evidence related to COVID-19 and rehabilitation. These guidelines should be interpreted, applied, and adjusted to vulnerable population such as elderly, local rules, and the scope of rehabilitation practices in each region ${ }^{13}$.

\section{GERIATRIC REHABILITATION APPROACH FOR RESPIRATORY PROBLEMS}

The lung function of elderly patients who survive COVID-19 can decrease significantly in the early stages of infection due to massive alveolar damage. Therefore, early pulmonary rehabilitation is very important in this stage. Timely respiratory rehabilitation interventions can improve prognosis, maximize functionality and improve QoL. One of the airway defence functions is coughing and mucocilliary transfer. Optimizing airway clearance will help prevent secondary infections ${ }^{10-13,44}$.

\section{PATIENTS IN REgULAR ISOLATION WARDS}

a) posture adjustments and prone position. Postural changes and prone position can increase gas exchange and reduce the incidence of pneumonia due 
to secondary bacterial infection by increasing drainage of secretions. Prone position can be used if the patient is conscious. In patients with mild ARDS, prone position for 2 hours every 12 hours is recommended ${ }^{11}$;

b) cough exercises are effective. Active, cooperative patients are given effective independent cough exercises such as active cycle breathing technique, or self-air stack (done without ambu bag, ending in "cough" or "huff") ${ }^{10}$;

c) patients with weak breathing muscles can cough with manual cough assist using the Ambu bag or with mechanical cough assist if there are no contraindications ${ }^{10,44}$.

\section{Patients With MEChanical Ventilation}

Clearance of the airway with mechanical ventilation starts from the time the patient was intubated:

a) posture adjustments and prone position. In patients with moderate and severe ARDS, a prone position for $12-16$ hours daily is recommended ${ }^{44}$;

b) techniques: vibration, percussion in all areas of the lung: anterior-posterior, and lateral;

c) if the patient has an adequate cough reflex, stimulation of the cough receptors will help develop the cough reflex ${ }^{10}$;

d) these must be done in the gravity support position;

e) provide cough relief for patients who are unconscious or in sedation by compressing the thorax or abdomen on expiration ${ }^{10,44}$;

f) patients who are conscious and can follow instructions are given inspiration-expiration-inspirationexpiration-inspiration-huffing exercises following the ventilator inspiration phase ${ }^{13}$;

g) mucus that are not discharged using the classic technique must be removed with manual cough assist or mechanical cough assist ${ }^{13}$.

\section{DECONDITIONING SYNDROME PREVENTION}

Elderly patients with COVID-19 will be in isolation period and this will reduce daily physical activities. This will also decrease the level of activity depends on how active the patient in physical activity prior to the disease. The benefits of reconditioning exercises as early as possible are to prevent the onset of deconditioning syndrome that can occur in many organ systems, including the musculoskeletal systems that can induce sarcopenia and frailty. In addition, reconditioning exercises will avoid build-up of mucus in the airways, prevent respiratory muscles dysfunction, improve breathing function, improve mechanical diaphragmatic function and maintain muscle function ${ }^{11-14}$.

\section{RECONDITIONING PATIENTS IN REGULAR ISOLATION CARE}

a. Stretching exercises: stretching the upper and lower limbs will prevent joint stiffness. Exercises can be done independently in patients with mild and general symptoms or passive exercises in patients with severe condition and in critically stable patients with a frequency of 1-2 times a day ${ }^{10}$.

b. Breathing muscle exercises. Breathing muscle exercises can be done using an inspiratory muscle trainer. Training load can be measured by 1 repetition maximum (RM) or $10 \mathrm{RM}$ after determining the Maximum Inspiratory Pressure (MIP). Diaphragmatic exercises can be done independently after supervised exercise. Breathing muscle exercises can only be performed on cooperative patients ${ }^{10}$.

c. Aerobic exercise. Aerobic exercise can be performed on patients with mild or generalized symptoms who are not feverish and are not breathless. Eligible patients can be tested using the sit to stand test. If desaturation occurs during exercise, supplemental oxygen can be given. If Oxygen Saturation (SpO2) is not increasing $(<93 \%)$, the exercise should be stopped ${ }^{12}$.

d. Peripheral muscle strengthening exercises. Squatting, bridging, ankle pumping are example of exercises that can maintain muscle tone ${ }^{10}$.

e. Breathing exercises. Deep breathing will help improve coughing capacity. The most important thing is to practice breathing control and relaxation for elderly patients experiencing shortness of breath. Educate and practice with the patients how to restrict the use the auxiliary breathing muscles, ways to conserve energy, how to control posture, and relaxation ${ }^{10,11}$.

\section{RECONDITIONING OF ELDERLY PATIENTS WITH COVID-19 IN THE ICU}

The main problem in pneumonia due to COVID-19 is oxygenation. Thus, all exercises that increase the load for ventilation perfusion must be screened using a strict medical criteria for stability ${ }^{44}$.

These criteria include oxygenation index of $>3.0$, stable hemodynamic with Mean Arterial Pressure (MAP) of $>65 \mathrm{cmH}_{2} \mathrm{O}$, patients on vasopressors without any increased dose, and Richmond Agitation Sedation Scale (RASS) score: -1 to $+2{ }^{44}$.

Exercise contraindications: all patients with unstable hemodynamic and respiratory functions should have no active exercise.

Geriatric rehabilitation programs:

a) Stretching exercises. This exercise can be done actively and passively, depending on the level of consciousness ${ }^{10}$;

b) Breath muscle exercises. Exercises in mechanically 
ventilated patients are designed to recruit the breathing muscle fibres whose breathing effort is still partially supported by mechanical ventilation, with the pressure support setting selected or with the system turned on and off. Repetition sets are performed according to oxygen tolerance and breathing effort monitored from the monitor and the patient's condition ${ }^{10}$;

c) Aerobic exercise. Aerobic exercise for stable patients in the ICU with mechanical ventilation can be performed using the upper or lower extremities. If ergo cycle arm is available, training can be given by measuring the intensity of the exercise from the bicycle training test ${ }^{12}$;

d) Strengthening exercises. Strengthening exercises in mechanically ventilated patients can be performed with active limb exercises. The goal is more to maintain muscle tone and eutrophy ${ }^{12}$;

e) Neuromuscular Electrical Stimulation (NMES). It can prevent peripheral muscle weakness in bed-ridden patients who cannot be given active exercise due to decreased consciousness, impaired cognition, and communication disorders. In addition, NMES in the abdominal wall muscles can be synchronized with inhalation, thus preventing expiratory muscle atrophy during the acute phase using mechanical ventilation. NMES therapy applied to the auxiliary respiratory muscles has been shown to improve arterial blood gases, blood pressure, and heart rate in ICU patients with respiratory distress ${ }^{45,46}$.

\section{EARLY MOBILIZATION IN THE ICU}

The principles and flow of early mobilization for elderly patients with COVID-19 in the ICU are similar to that for non-COVID-19 patients, including patients on mechanical ventilation. Determining whether the patient is in a stable conditions is an absolute requirement, and this can be done using an early mobilization screening algorithm. Absolute contraindication criteria include MAP of $<65 \mathrm{cmH}_{2} \mathrm{O}$ and oxygenation index of $<3.0$. The patient can start performing gradual exercise on the bed, followed by exercising while sitting in a chair, walking with assistance, and finally walking independently after going through the acute phase ${ }^{11}$.

Patients with COVID-19 will require a more complex effort and team considering the complexity of the personal safety equipment that all health workers who treat patients must use. Monitoring is performed before, during and after the mobilization exercise. Fraction of Inspired Oxygen $\left(\mathrm{FiO}_{2}\right)$ can be increased during the training process if there is desaturation and exercise can be stopped if the $\mathrm{FiO}_{2}$ is not corrected. Exercise assistance can also be given through increasing ventilatory support ${ }^{10,11,44}$.

\section{MusculoskeletAL ASPECT}

The number of patients who develop sarcopenia during hospitalization is relatively high. Sarcopenia can be classified as primary sarcopenia affected by age and secondary sarcopenia affected by inactivity, malnutrition, and disease-related sarcopenia, such as acquired weakness from ICU treatment. Almost all patient in the ICU are at risk of losing muscle mass due to prolonged bed rest. In sarcopenia, muscle mass is one of the important things to consider, which can be assessed using MRI, CT, and ultrasonography or anthropometric measurement. However, the most commonly used, lowcost, and easily-accessible method to measure muscle mass is using the bioelectric impedance analysis (BIA). Muscle strength can also be assessed using handgrip strength. A variety of additional clinical outcomes have been reported, including in-hospital mortality, number of days being mechanically-ventilated, length of ICU/ hospital stay, readmission rate and post-discharge mortality, but data on musculoskeletal impairment including sarcopenia are limited 47,48 .

The resistance exercise is an effective means to combat the loss of muscle mass and function in various populations. A recent study highlighted the potential of resistance exercise in improving key physiological outcomes in older, chronically-ill individuals. Resistance exercise impacts sarcopenia through several mechanisms, both in the muscular and neuromotor levels ${ }^{49-50}$.

\section{NUtrition ASPECT}

Despite efforts to prevent and treat malnutrition, the prevalence of disease-related malnutrition remains consistent. On the other hand, the mortality rate for patients during hospitalization and post-discharge have significantly lowered owing to the initiation of high protein oral nutritional supplement ${ }^{51}$.

For maintaining or protecting nutritional status in elderly patients, targeted oral nutritional supplement is needed. This can be administered using a variety of supplements containing different components, including vitamin $\mathrm{D}$, higher caloric content, amino acids, protein and beta-hydroxy-beta-methyl butyrate (HMB) ${ }^{51-52}$.

\section{PSYCHOSOCIAL ASPECTS RELATED TO ELDERLY PATIENTS WITH COVID-19}

Screening of anxiety and depression status in elderly patient with COVID-19 is important for rehabilitation programs. Psychosocial disorders can occur because of the burden of illness, stigma or due to isolation from family, hobbies, and work ${ }^{15,37,38}$. The loss of motivation due to changes in mental status or cognition related to 
COVID-19 will become an obstacle in implementing the rehabilitation program ${ }^{11-15,43}$.

Medical staff must communicate with patients, which helps reduce anxiety and depression. In addition, sleep aids, such as earplugs, eye patches, soft music, and sedatives, can be used to improve a quality night-time sleep $15,37,38,42,43$.

The assistance of psychologists and social workers in every stage of treatment is important to help solve the psychosocial aspects of elderly patients with COVID-19 42,43,52,53. A number of negative stigmas persists in the society, especially directed towards sufferers of COVID-19. Therefore it is necessary to educate the public through health and government policy ${ }^{37,38,53}$. Periodic evaluations are conducted to plan a suitable geriatric rehabilitation program for each individual.

\section{CONCLUSIONS}

Severe acute respiratory syndrome coronavirus 2 is a new virus from the coronaviridae family that causes COVID-19 and is responsible for a deadly pandemic. The elderly is a vulnerable population with high infection and mortality rates, as indicated by the fact that $62-80 \%$ of deaths, $81 \%$ ARDS, and $94 \%$ use of mechanical ventilation occurring in patients over 60 years of age.

The most common symptoms reported in elderly COVID-19 patients include fever (78.3\%) and cough (56.7\%). Initially patients experience fever, fatigue, dry cough, and gradually develop dyspnoea. Some symptomatic patients develop ARDS, septic shock, and even death.

Complications commonly found in the elderly during hospitalization are bacterial infections, ARDS, ACS, and liver enzyme abnormalities. In addition, elderly patients also have higher comorbidity than the whole population. These comorbidities are hypertension, diabetes, cardiovascular disease, COPD, and cerebrovascular disease, which exacerbate COVID-19 infection. Therefore, the elderly population is very vulnerable to contracting COVID-19, and thus it is very important to prevent COVID-19 in this population.

Rapid response and rehabilitation programs, particularly during the acute, sub-acute and long-term care phase, are required to reduce disability, accelerate recovery, and optimize function. Therefore, COVID-19 rehabilitation needs are divided according to the treatment phase, with the goal of relieving symptoms, assisting in the success of mechanical ventilation weaning process, preventing deconditioning of the airway and other organ systems, and managing psychosocial aspects, particularly in vulnerable and high-risk populations such as elderly patient.
Management of elderly patient with COVID-19 need to direct its attention to the physiological process of ageing, comorbidities, and musculoskeletal issue such as sarcopenia. In addition, the psychosocial aspects of elderly patients with COVID-19 need more attention and assistance from psychologists and medical social workers in every phase of care.

In conclusion, the role of geriatric rehabilitation for the elderly with COVID-19 is to optimize their role of function, participation and increase Quality of Life. This study is expected to provide knowledge and hopefully may become references used in developing guidelines for planning geriatric rehabilitation management of elderly patients with COVID-19.

\section{Ethical consideration \\ None.}

\section{Acknowledgement}

None.

\section{Funding}

This research received no external funding.

\section{Conflict of interest}

The Authors declare no conflict of interest.

\section{References}

1 Shahid Z, Kalayanamitra R, McClafferty B, et al. COVID-19 and older adults: what we know. J Am Geriatr Soc 2020;68:926-929. https://doi.org/10.1111/jgs/16472.

2 Worldometer. COVID-19 coronavirus pandemic 2020 (https://www.worldometers.info/coronavirus).

3 Wang L, He W, Yu X, et al. Coronavirus disease 2019 in elderly patients: characteristics and prognostic factors based on 4-week follow-up. J Infect 2020;80:639-645. https://doi.org/10.1016/j.jinf.2020.03.019

4 Li LQ, Huang T, Wang YQ, et al. COVID-19 patients' clinical characteristics, discharge rate, and fatality rate of meta-analysis. J Med Virol 2020;92:577-583 https://doi. org/10.1002/jmv.25757

5 Kenneth Mclntosh M. Coronavirus disease 2019 (COVID-19) epidemiology, virology, clinical features, diagnosis, and prevention. UpToDate 2020 (https://www.uptodate. com).

6 Niu S, Tian S, Lou J, et al. Clinical characteristics of older patients infected with COVID-19: a descriptive study. Arch Gerontol Geriatr 2020;89:104058. https://doi. org/20.1016/j.archger.2020.104058

7 Yang $X, Y u, Y, X u$ J, et al. Clinical course and outcomes of critically ill patients with SARS-CoV-2 pneumonia in Wuhan, China: a single-centered, retrospective, observational study. Lancet Respir Med 2020;8:475-481. https://doi. org/10.1016/S2213-2600(20)30079-5 
8 Liu K, Chen Y, Lin R, et al. Clinical features of COVID-19 in elderly patients: a comparison with young and middleaged patients. J Infect 2020;80:e14-e18. https://doi. org/10.1016/j.jinf.2020.03.005

9 Boldrini P, Bernetti A, Fiore P, et al. Impact of COVID-19 outbreak on rehabilitation services and Physical and Rehabilitation Medicine (PRM) physicians' activities in Italy. An official document of the Italian PRM Society (SIMFER). Eur J Phys Rehabil Med 2020;56:316-318. https://doi. org/10.23736/S1973-9087.20.06256-5

10 Liu K, Zhang W, Yang Y, et al. Respiratory rehabilitation in elderly patients with COVID-19: a randomized controlled study. Complement Ther Clin Pract 2020;39:101166. https://doi.org/10.1016/j/ctcp.2020.101166

11 Zhu C, Wu Y, Liu H, et al. Early pulmonary rehabilitation for SARS-CoV-2 pneumonia: experience from an intensive care unit outside of the Hubei province in China. Heart Lung 2020;49:449-450. https://doi.org/10.1016/j. hrtlng.2020.04.007

12 Carda S, Invernizzi M, Bavikatte G, et al. The role of physical and rehabilitation medicine in the COVID-19 pandemic: the clinician's view. Ann Phys Rehabil Med 2020;63:554556. https://doi.org/10.1016/j.rehab.2020.04.001

13 Pan American Health Organization WHO. Rehabilitation consideration during the COVID-19 outbreak [e-book] PAHO, 2020. (https://www.paho.org/en/topics/rehabilitation).

14 Sheehy LM. Considerations for postacute rehabilitation for survivors of COVID-19. JMIR Public Health Surveill 2020;6:e19462. https://doi.org/10.2196/19462

15 World Health Organization (WHO). Clinical management of COVID-19. WHO 2020 (https://apps.who.int/iris/ bitstream/handle/10665/332196/WHO-2019-nCoV-clinical-2020.5-eng.pdf)

16 Wu C, Chen X, Cai Y, et al. risk factors associated with acute respiratory distress syndrome and death in patients with coronavirus disease 2019 pneumonia in Wuhan, China. JAMA Intern Med 2020;180:934-943. https://doi. org/10.1001/jamainternmed.2020.0994

17 Guan WJ, Ni ZY, Hu Y, et al. Clinical characteristics of coronavirus disease 2019 in China. N Engl J Med 2020;382:1708-1720. https://doi.org/10.1056/ NEJMoa2002032

18 Li G, Fan Y, Lai Y, et al. Coronavirus infections and immune responses. J Med Virol 2020;92:424-432. https:// doi.org/10.1002/jmv.25685

19 Burian E, Jungmann F, Kaissis GA, et al. Intensive care risk estimation in COVID-19 pneumonia based on clinical and imaging parameters: experiences from the Munich Cohort. J Clin Med 2020;9:1514. https://doi.org/10.3390/ jcm9051514

20 Leung C. Risk factors for predicting mortality in elderly patients with COVID-19: a review of clinical data in China. Mech Ageing Dev 2020;188:111255. https://doi. org/10.1016/j.mad.2020.111255

21 Roubenoff R. The pathophysiology of wasting in the elderly. J Nutr 1999;129:256S-259S. https://doi.org/10.1093/ $\mathrm{jn} / 129.1 .256 \mathrm{~S}$
22 Roubenoff R, Hughes VA. Sarcopenia: current concepts. J Gerontol A Biol Sci Med Sci 2000;55:M716-M724. https:// doi.org/10.1093/gerona/gg.12.m716

23 Gale CR, Martyn CN, Cooper C, et al. Grip strength, body composition, and mortality. Int J Epidemiol 2007;36:228235 https://doi.org/10.1093/ije/dyl224

24 Sayer AA, Syddall HE, Martin HJ, et al. Is grip strength associated with health- related quality of life? Findings from the Hertfordshire Cohort Study. Age Ageing 2006;35:409415. https://doi.org/10.1093/ageing/afl024

25 Janssen I, Heymsfield SB, Ross R. Low relative skeletal muscle mass (sarcopenia) in older persons is associated with functional impairment and physical disability. J Am Geriatr Soc 2002;50:889-896. https://doi. org/10.1046/j.1532-5415.2002.50216.x

26 Janssen I, Shepard DS, Katzmarzyk PT, et al. The healthcare costs of sarcopenia in the United States. J Am Geriatr Soc 2004;52:80-85. https://doi. org/10.1111/j.1532-5415.2004.52014.x

27 Cruz-Jentoft AJ, Landi F, Topinková E, et al. Understanding sarcopenia as a geriatric syndrome. Curr Opin Clin Nutr Metab Care 2010;13:1-7 https://doi.org/10.1097/ MCO.0b013e328333c1c1

28 Onder G, Palmieri L, Vanacore N, et al. Nonrespiratory complications and obesity in patients dying with COVID-19 in Italy. Obesity 2021;29:20-23. https://doi.org/10.1002/ oby. 23007

29 Barone M, Viggiani MT, Anelli MG, et al. Sarcopenia in patients with rheumatic diseases: prevalence and associated risk factors. J Clin Med 2018;7. https://doi.org/10.3390/ jcm7120504

30 Ngeuleu A, Allali F, Medrare L, et al. Sarcopenia in rheumatoid arthritis: prevalence, influence of disease activity and associated factors. Rheumatol Int 2017;37:1015-1020. https://doi.org/10.1007/s00296-017-3665-x

31 Gupta S, Dhillon RJS, Hasni S. Sarcopenia: A rheumatic disease? Rheum Dis Clin North Am 2018;44:393-404. https://doi.org/10.1016/j.rdc.2018.03.001

32 Ali AM, Kunugi H. Screening for sarcopenia (physical frailty) in the COVID-19 era. Int J Endocrinol 2021;2021:1-16. https://doi.org/10.1155/2021/5563960

33 Marzetti E, Calvani R, Tosato M, et al. SPRINTT Consortium physical activity and exercise as countermeasures to physical frailty and sarcopenia. Aging Clin Exp Res 2017;29:3542. https://doi.org/10.1007/s40520-016-0705-4

34 Landi F, Russo A, Cesari M, et al. Walking one hour or more per day prevented mortality among older persons: results from ilSIRENTE study. Prev Med 2008;47:422-426. https://doi.org/10.1016/j.ypmed.2008.06.020

35 Grassi C, Landi F, Delogu G. Lifestyles and ageing: targeting key mechanisms to shift the balance from unhealthy to healthy ageing. Stud Health Technol Inform 2014;203:99 111. https://doi.org/10.3233/978-1-61499-425-1-99 
36 Vetrano DL, Martone AM, Mastropaolo S, et al. Prevalence of the seven cardiovascular health metrics in a Mediterranean country: results from a cross-sectional study. Eur J Public Health 2013;23:858-862. https://doi.org/10.1093/ eurpub/ckt130

37 Morrow-Howell N, Galucia N, Swinford E. Recovering from the COVID-19 pandemic: a focus on older adults. J Aging Soc Policy 2020;32526-535. https://doi.org/10.1080/089 59420.2020 .1759758

38 Pan American Health Organization WHO. Policy brief: the impact of COVID-19 on older persons [e-book] $\mathrm{PAHO}, \quad 2020 \quad$ (https://www.paho.org/en/documents/ policy-brief-impact-covid-19-older-persons).

39 Lew HL, Oh-Park M, Cifu DX. The war on COVID-19 pandemic: role of rehabilitation professionals and hospitals. Am J Phys Med Rehabil 2020;99:571-572. https://doi. org/10.1097.PHM.0000000000001460

40 Tur BS, Evcik D. Is physical medicine and rehabilitation needed much more for COVID-19 pandemic? Turk J Phys Med Rehabil 2020;66:101-103. https://doi.org/10.5606/ tftrd.2020.60012

41 Fontes WHA, Júnior JG, de Vasconcelos CAC, et al. Impacts of the SARS-CoV-2 pandemic on the mental health of the elderly. Front Psychiatry 2020;11:841. https://doi. org/10.3389/fpsyt.2020.00841

42 Meng $\mathrm{H}, \mathrm{Xu} \mathrm{Y}$, Dai J, et al. Analyze the psychological impact of COVID-19 among the elderly population in China and make corresponding suggestions. Psychiatry Res 2020;289:112983. https://doi.org/10.1016/j. psychres.2020.112983

43 Parlapani E, Holeva V, Nikopoulou VA, et al. Intolerance of uncertainty and loneliness in older adults during the COVID-19 pandemic. Front Psychiatry 2020;11:842. https:// doi.org/10.3389/fpsyt.2020.00842

44 Alhazzani W, Møller MH, Arabi YM, et al. Surviving sepsis campaign: guidelines on the management of critically ill adults with coronavirus disease 2019 (COVID-19). Intensive Care Med 2020;46:854-887. https://doi.org/10.1007/ s00134-020-06022-5
45 Heunks L. NMES to prevent respiratory muscle atrophy in mechanically ventilated patients. In: Medicine USNLO, 2020 (https://clinicaltrials.gov/ct2/show/NCT03453944).

46 Kurtoglu DK, Tastekin N, Birtane M, et al. Effectiveness of neuromuscular electrical stimulation on auxiliary respiratory muscles in patients with chronic obstructive pulmonary disease treated in the intensive care unit. Turk J Phys Med Rehab 2015;61:12-17. https://doi.org/10.5152/ tftrd.2015.04378

47 Kizilarslanoglu MC, Kuyumcu ME, Yesil Y, et al. Sarcopenia in critically ill patients. J Anesth 2016;30:884-890. https:// doi.org/10.1007/s00540-016-2211-4

48 Gropper S, Hunt D, Chapa DW. Sarcopenia and psychosocial variables in patients in intensive care units: the role of nutrition and rehabilitation in prevention and treatment. Crit Care Nurs Clin North Am 2019;31:489-499. https:// doi.org/10.1016/j.cnc.2019.07.004

49 English KL, Jones DP. Protecting muscle mass and function in older adults during bed rest. Curr Opin Clin Nutr Metab Care 2010;13:34-39. https://doi.org/ 10.1097/ MCO.0b013e328333aa66

50 Beas-Jiménez J de D, López-Lluch G, Sánchez-Martínez I, et al. Sarcopenia: implications of physical exercise in its pathophysiology, prevention and treatment. Rev Andal Med Deporte 2011;4:158-66.

51 Deutz NE, Matheson EM, Matarese LE, et al. Readmission and mortality in malnourished, older, hospitalized adults treated with a specialized oral nutritional supplement: A randomized clinical trial. Clin Nutr 2016;35:18-26. https:// doi.org/10.1016/j.clnu.2015.12.010

52 Jiang R, Wang L, Wang P. Guidance for coronavirus disease 2019-prevention, control, diagnosis and management. In: Xian DU, Chuxiao DU, Eds. Republic of China: People's Medical Publishing House 2020.

53 Petretto DR, Pili R. Ageing and COVID-19: what is the role for elderly people? Geriatrics (Basel) 2020;5:25. https:// doi.org/10.3390/geriatrics5020025 